\title{
Sequential soil washing with mixed biosurfactants is suitable for simultaneous removal of multi-metals from soils with different properties, pollution levels and ages
}

\author{
Zygmunt Mariusz Gusiatin ${ }^{1}$ (D) Maja Radziemska² - Alicja Żochowska ${ }^{1}$
}

Received: 7 February 2019 / Accepted: 7 August 2019 / Published online: 16 August 2019

(c) The Author(s) 2019

\begin{abstract}
In this study, plant (SAP, TAN) and microbial (RAM) biosurfactants were applied to two soils, in single or sequential soil washing. Soil 1 was moderately acidic, with higher content of organic matter and $\mathrm{HMs}(\mathrm{Cd}, \mathrm{Cu}, \mathrm{Ni}, \mathrm{Pb}$ and $\mathrm{Zn})$, and was aged for 24 months. Soil 2 was alkaline, with lower content of organic matter and HMs, and was aged for 1 month. The stability of the HMs (as $I_{\mathrm{R}}$ ), except for $\mathrm{Pb}$, was higher in soil 1 than in soil 2, but the rankings of $\mathrm{HM}$ stability were similar: $\mathrm{Cu}>\mathrm{Ni} \approx \mathrm{Pb}>\mathrm{Zn}>\mathrm{Cd}$ (soil 1) and $\mathrm{Cu}>\mathrm{Pb}>\mathrm{Ni}>\mathrm{Zn}>\mathrm{Cd}$ (soil 2). The HMs were removed more efficiently from soil 2 than from soil 1 , mainly from the readily available fraction and partially from the reducible fraction. $\mathrm{Cu}(0.3-0.5$ times $), \mathrm{Ni}$ (0.4-1.1 times) and $\mathrm{Zn}(0.5-1.0$ times) showed the largest increases in stability after soil washing with SAP. With a single washing, SAP and TAN were the least effective for Pb removal (18-31\% and 11-35\%, respectively), while RAM was the most effective for $\mathrm{Cd}(69-73 \%)$ and $\mathrm{Pb}$ (58-63\%) removal. Sequential soil washing, especially with SAP followed by RAM, was the best choice for simultaneous removal of multi-HMs.
\end{abstract}

Keywords Biosurfactants $\cdot$ Soil remediation $\cdot$ Single and sequential soil washing $\cdot$ Metal fractionation and stability Cluster analysis

$\begin{array}{ll}\text { Abbreviations } \\ \text { SAP } & \text { Saponin } \\ \text { TAN } & \text { Tannic acid } \\ \text { RAM } & \text { Rhamnolipids } \\ \text { HMs } & \text { Heavy metals } \\ I_{\mathrm{R}} & \text { Reduced partition index }\end{array}$

\section{Introduction}

Soil contamination with heavy metals (HMs) is a global problem; it occurs mainly in highly developed countries like the USA, Australia, China, Germany or Sweden. However,

Zygmunt Mariusz Gusiatin

mariusz.gusiatin@uwm.edu.pl

1 Department of Environmental Biotechnology, Faculty of Environmental Sciences, University of Warmia and Mazury in Olsztyn, Słoneczna St. 45G, 10-719 Olsztyn, Poland

2 Faculty of Civil and Environmental Engineering, Warsaw University of Life Sciences, Nowoursynowska St. 159, 02-776 Warsaw, Poland
HM concentrations in soils can also be high in less developed countries (e.g., Pakistan, India, Bangladesh), mainly as a result of using untreated wastewater for crop irrigation (Khalid et al. 2017).

Usually, soils are not contaminated with a single HM, but are co-contaminated with different HMs. Some of the HMs commonly present in soils are nickel $(\mathrm{Ni})$, lead $(\mathrm{Pb})$, cadmium $(\mathrm{Cd})$, copper $(\mathrm{Cu})$ and zinc $(\mathrm{Zn})$. Contaminated sites have wide variations in HM concentrations, which affect the level of soil contamination. In polluted soils around the world, Cd concentrations range from 14 to $42 \mathrm{mg} / \mathrm{kg}$; those of $\mathrm{Pb}$ range from 302 to $4500 \mathrm{mg} / \mathrm{kg}$; those of $\mathrm{Zn}$, from 393 to $3833 \mathrm{mg} / \mathrm{kg}$; Ni, from 153 to $2603 \mathrm{mg} / \mathrm{kg}$; and $\mathrm{Cu}$, from 235 to $35,582 \mathrm{mg} / \mathrm{kg}$ (Khalid et al. 2017). Such variations in HM concentrations can affect the efficiency and feasibility of soil remediation technologies. Therefore, it is reasonable to further develop soil remediation technologies for multiHM-contaminated soils.

For treatment of HM-contaminated soils, soil washing is still considered both an innovative remediation method (Liu et al. 2017) and, owing to its high efficiency, one of the most cost-effective soil remediation technologies (Khalid et al. 2017). Although EDTA is most commonly used in 
soil washing studies (Bilgin and Tulun 2016, Wei et al. 2016, Naghipour et al. 2017), the use of alternative washing agents, such as plant and microbial biosurfactants, is still attractive.

Rhamnolipids (RAM) are the most intensively studied glycolipid biosurfactant. They are produced by Pseudomonas aeruginosa and are composed of one or two rhamnose groups in the hydrophilic moiety, and up to three hydroxy fatty acids (C8-C14) in the hydrophobic moiety (Wan et al. 2015). RAM are widely used in many fields, such as oil recovery, food production, cosmetics, and pharmaceutics (Liu et al. 2018). In environmental remediation, they can act as ligands and have a strong affinity for HMs due to their carboxyl groups. Up to now, most studies on the use of RAM have involved $\mathrm{Cu}, \mathrm{Cd}, \mathrm{Ni}, \mathrm{Pb}$ or $\mathrm{Zn}$ removal from soils via soil washing (at varying $\mathrm{pH}$, concentrations of RAM or washing times) or soil flushing (at different concentration of RAM, flushing time or flow rate) (Mulligan and Wang 2006; Juwarkar et al. 2007; Venkatesh and Vedaraman 2012; Wan et al. 2015).

Saponin (SAP) is a kind of glycoside and, thus, is a secondary plant metabolite. As a nonionic biosurfactant, SAP has diverse physicochemical properties that have been successfully used in a number of commercial applications, including soil washing. Previous studies indicate that, for removal of HMs from soil, SAP needs to be used at acidic $\mathrm{pH}$ and relatively high concentrations $(\sim 3 \%)$, and for relatively short extraction times (3-6 h) (Hong et al. 2002; Gusiatin and Klimiuk 2012).

Tannic acid (TAN) is a naturally occurring plant polyphenol that is a hydrolyzable tannin. Although TAN is able to form complexes with HMs because it has numerous phenolic hydroxyl groups (Friman et al. 2004), its applications in soil washing have not been completely investigated. So far, TAN has been found useful as a washing agent only for soils contaminated with a mixture of $\mathrm{Cu}, \mathrm{Pb}$ and $\mathrm{Zn}$ or with $\mathrm{As}$, and the operational conditions for HM removal via soil washing with TAN are similar to those applied with SAP (Gusiatin et al. 2014; Gusiatin 2014).

Most available studies on the use of RAM, SAP or TAN as washing agents have focused on optimizing the removal of one or two HMs from soils, not mixtures of three or more HMs. When assessing the effectiveness of microbial and plant biosurfactants for soil washing, not only the operational conditions for removal of HMs from different soils need to be taken into consideration, but also the level of HM pollution in soil (because of the limited number of active sites that biosurfactants have available for complexing HMs) and the age of the contaminated soil (due to changes in HM distribution over time). Kulikowska et al. (2015) found that the efficiency of $\mathrm{Cu}, \mathrm{Ni}$ and $\mathrm{Zn}$ removal with a solution of humic substances from sewage sludge compost decreased as soil age increased, while the efficiency of $\mathrm{Pb}$ and $\mathrm{Cd}$ removal did not depend on soil aging. When testing synthetic washing agents, some authors found that a combination of acid and chelator could remove HMs with higher efficiency than any single acid or chelator (Yang et al. 2012). Thus, soil washing with combinations of biosurfactants that have different affinities for specific HMs could be important, especially for treatment of multi-HM-contaminated soils. At present, data on the use of RAM, SAP and TAN for removing multi-HMs from soils with different pollution levels and ages are limited, as is the use of these biosurfactants in combination for removing HMs via sequential soil washing.

Thus, the aim of this study was to compare the efficiency of simultaneous removal of multi-HMs $(\mathrm{Cd}, \mathrm{Cu}, \mathrm{Ni}, \mathrm{Pb}$ and $\mathrm{Zn}$ ) from different soils (based on soil properties, total HM content and aging time) with RAM, SAP and TAN, and to determine the effect of these biosurfactants on HM redistribution, in terms of HM mobility and stability. Moreover, the effect on HM removal of sequential soil washing with the same or different classes of biosurfactant was determined to select the most effective sequence of washing solutions for simultaneous multi-HM removal.

\section{Materials and methods}

\section{Soils}

In this study, two soils spiked with HMs were used for soil washing with biosurfactants. The soils were collected from the surface level of soil (depth $0-30 \mathrm{~cm}$ ) in Warmia and Mazury Province, north-eastern Poland. Then, the soils were air dried and ground to pass through a 1-mm sieve. Next, each soil (2 kg) was spiked with a mixture of five $\mathrm{HMs}$ : $\mathrm{Cd}, \mathrm{Cu}, \mathrm{Ni}, \mathrm{Pb}$ and $\mathrm{Zn}$. To obtain different total HM concentrations in soils, the following weights of HM salts (Sigma-Aldrich) were dissolved in distilled water and added to the soils: $0.1372 \mathrm{~g} \mathrm{Cd}\left(\mathrm{NO}_{3}\right)_{2} \cdot 4 \mathrm{H}_{2} \mathrm{O}$, $3.6602 \mathrm{~g} \mathrm{Cu}\left(\mathrm{NO}_{3}\right)_{2} \cdot 2.5 \mathrm{H}_{2} \mathrm{O}, 2.4658 \mathrm{~g} \mathrm{Ni}\left(\mathrm{NO}_{3}\right)_{2} \cdot 6 \mathrm{H}_{2} \mathrm{O}$, $6.3940 \mathrm{~g} \mathrm{~Pb}\left(\mathrm{NO}_{3}\right)_{2}$ and $9.0963 \mathrm{~g} \mathrm{Zn}\left(\mathrm{NO}_{3}\right)_{2} \cdot 6 \mathrm{H}_{2} \mathrm{O}$ (soil 1); and $0.0549 \mathrm{~g} \mathrm{Cd}\left(\mathrm{NO}_{3}\right)_{2} \cdot 4 \mathrm{H}_{2} \mathrm{O}, 1.4641 \mathrm{~g} \mathrm{Cu}\left(\mathrm{NO}_{3}\right)_{2} \cdot 2.5 \mathrm{H}_{2} \mathrm{O}$, $0.9863 \mathrm{~g} \mathrm{Ni}\left(\mathrm{NO}_{3}\right)_{2} \cdot 6 \mathrm{H}_{2} \mathrm{O}, 1.5985 \mathrm{~g} \mathrm{~Pb}\left(\mathrm{NO}_{3}\right)_{2}$ and $3.6385 \mathrm{~g}$ $\mathrm{Zn}\left(\mathrm{NO}_{3}\right)_{2} \cdot 6 \mathrm{H}_{2} \mathrm{O}$ (soil 2). After spiking, the soils were aged at room temperature and maintained at $60-65 \%$ of their maximum water holding capacity. As it can be assumed that HMs that are present at lower concentrations in soil require a shorter time to achieve equilibrium than HMs that are present at higher concentrations, the length of aging differed depending on the soil. Soil 1, which had higher HM concentrations, was allowed to age for 24 months, whereas soil 2, with lower HM concentrations, was allowed to age for 1 month. During the aging process, the containers were weighed each week and the appropriate amount of water was added if necessary. For 
homogenous HM distribution, the soil was gently mixed once a week. After aging, the soils were dried, crushed and kept in tightly closed plastic containers for further experiments.

The physicochemical characteristics of the spiked soils are presented in Table 1. Although the soils had the same texture, they differed in $\mathrm{pH}$ and organic matter content. Soil 1 had higher conductivity than soil 2 , and in soil 1 , all HMs exceeded Polish limits for industrial areas $(15 \mathrm{mg} \mathrm{Cd} /$ $\mathrm{kg}, 600 \mathrm{mg} \mathrm{Cu} / \mathrm{kg}, 500 \mathrm{mg} \mathrm{Ni} / \mathrm{kg}, 600 \mathrm{mg} \mathrm{Pb} / \mathrm{kg}, 2000 \mathrm{mg}$ $\mathrm{Zn} / \mathrm{kg}$ ), whereas in soil 2, only $\mathrm{Pb}$ was above the limit.

Table 1 Selected physicochemical properties of spiked soils (values are given as means, $n=3, \pm$ standard deviation)

\begin{tabular}{llll}
\hline Characteristic & Unit & Soil 1 & Soil 2 \\
\hline Texture & - & Sandy clay loam & \\
$\mathrm{pH}_{\mathrm{KCl}}$ & - & $5.9 \pm 0.3$ & $7.7 \pm 0.2$ \\
Conductivity & $\mathrm{mS} / \mathrm{cm}$ & $1.6 \pm 0.1$ & $0.1 \pm 0.0$ \\
Organic matter & $\%$ & $5.67 \pm 0.21$ & $4.02 \pm 0.10$ \\
Cation exchange capacity & $\mathrm{cmol} / \mathrm{kg}$ & $38.8 \pm 1.3$ & $39.7 \pm 0.9$ \\
Before spiking & & & \\
$\mathrm{Cd}$ & $\mathrm{mg} / \mathrm{kg}$ & $0.2 \pm 0.02$ & 0.0 \\
$\mathrm{Cu}$ & $\mathrm{mg} / \mathrm{kg}$ & $12.0 \pm 2.3$ & $1.6 \pm 0.06$ \\
$\mathrm{Ni}$ & $\mathrm{mg} / \mathrm{kg}$ & $17.9 \pm 1.7$ & $4.8 \pm 0.2$ \\
$\mathrm{~Pb}$ & $\mathrm{mg} / \mathrm{kg}$ & $13.5 \pm 1.3$ & $0.9 \pm 0.01$ \\
$\mathrm{Zn}$ & $\mathrm{mg} / \mathrm{kg}$ & $20.3 \pm 1.9$ & $6.1 \pm 0.2$ \\
$\mathrm{After} \mathrm{spiking}$ & & & \\
$\mathrm{Cd}$ & $\mathrm{mg} / \mathrm{kg}$ & $46 \pm 1.4$ & $16 \pm 0.8$ \\
$\mathrm{Cu}$ & $\mathrm{mg} / \mathrm{kg}$ & $1019 \pm 19.3$ & $305 \pm 10.4$ \\
$\mathrm{Ni}$ & $\mathrm{mg} / \mathrm{kg}$ & $534 \pm 2.9$ & $166 \pm 8.5$ \\
$\mathrm{~Pb}$ & $\mathrm{mg} / \mathrm{kg}$ & $4133 \pm 140$ & $854 \pm 16.4$ \\
$\mathrm{Zn}$ & $\mathrm{mg} / \mathrm{kg}$ & $2278 \pm 41.4$ & $683 \pm 1.4$ \\
\hline
\end{tabular}

\section{Biosurfactants}

Three commercially purchased biosurfactants (SAP, TAN and RAM) were tested as soil washing agents. SAP (product no. 84510) is nonionic biosurfactant in the form of a powder, with a sapogenin content of $8-25 \%$ (Sigma-Aldrich). TAN (product no. 16201) is a natural polyphenolic compound that is in the form of a solid with a molecular weight of $1701.2 \mathrm{~g} /$ mol, a light yellow to tan color, a faint odor, and a purity of $90.8 \%$.

RAM is a $25 \%$ aqueous solution that contains a mixture of anionic rhamnolipids of type $\mathrm{R} 1\left(\mathrm{C}_{26} \mathrm{H}_{48} \mathrm{O}_{9}\right)$ and type $\mathrm{R} 2$ $\left(\mathrm{C}_{32} \mathrm{H}_{58} \mathrm{O}_{13}\right)$ that is sold under the trade name of JBR425. It is a dark brown, viscous liquid. JBR425 is produced from sterilized and centrifuged fermentation broth, which has had all protein removed (Jeneil Biosurfactant Co LLC, USA). All three biosurfactants were used without further purification.

Based on previous experiments, it was estimated that the optimum concentration of plant biosurfactants (SAP, TAN) for removal of HMs from soil is 3\% (Gusiatin et al. 2014). RAM was used at the same concentration as SAP and TAN. The $3 \%$ solution was prepared by dissolving $30 \mathrm{~g}$ of SAP or TAN, or $120 \mathrm{~g}$ of RAM in $1 \mathrm{~L}$ of distilled water. Selected properties of the biosurfactants are given in Table 2. Although these biosurfactants were used at the same $\%$ concentration, the concentration of total organic carbon was higher with RAM than with the plant biosurfactants. The RAM solution was neutral, whereas the plant biosurfactant solutions were acidic. In contrast to the TAN solution, the SAP and RAM solutions were saline, which is likely due to the purity of these biosurfactants. RAM were more efficient at decreasing the surface tension of water than SAP and TAN. The biosurfactant solutions should not be an additional source of soil contamination with HMs because the total concentrations of HMs in the solutions were low;
Table 2 Selected characteristics of biosurfactant solutions (values are given as means, $n=3, \pm$ standard deviation)

\begin{tabular}{lllll}
\hline Characteristic & Unit & SAP & TAN & RAM \\
\hline Concentration & $\%(\mathrm{w} / \mathrm{v})$ & 3 & 3 & 3 \\
Total organic carbon (TOC) & $\mathrm{g} / \mathrm{L}$ & $12.7 \pm 0.6$ & $14.7 \pm 1.1$ & $24.5 \pm 0.5$ \\
Critical micelle concentration (CMC) & $\mathrm{g} / \mathrm{L}$ & $0.9 \pm 0.1$ & $12.7 \pm 0.3$ & $0.022 \pm 0.001$ \\
$\mathrm{pH}$ & - & $5.58 \pm 0.12$ & $4.24 \pm 0.15$ & $6.82 \pm 0.09$ \\
Conductivity & $\mathrm{mS} / \mathrm{cm}$ & $29.0 \pm 0.1$ & $1.5 \pm 0.1$ & $25.1 \pm 0.2$ \\
Surface tension & $\mathrm{mN} / \mathrm{m}$ & $38.7 \pm 0.6$ & $41.5 \pm 0.9$ & $22.4 \pm 0.5$ \\
Interfacial tension $^{\mathrm{a}}$ & $\mathrm{mN} / \mathrm{m}$ & 6.0 & 4.5 & 4.5 \\
Density & $\mathrm{g} / \mathrm{mL}$ & 1.098 & 1.085 & 1.076 \\
$\mathrm{Cd}$ & $\mathrm{mg} / \mathrm{L}$ & $0 \pm 0.0$ & $0 \pm 0.0$ & $0.03 \pm 0.0$ \\
$\mathrm{Cu}$ & $\mathrm{mg} / \mathrm{L}$ & $0.95 \pm 0.09$ & $1.07 \pm 0.12$ & $0.51 \pm 0.06$ \\
$\mathrm{Ni}$ & $\mathrm{mg} / \mathrm{L}$ & $0.18 \pm 0.04$ & $0 \pm 0.0$ & $0.18 \pm 0.07$ \\
$\mathrm{~Pb}$ & $\mathrm{mg} / \mathrm{L}$ & $0.33 \pm 0.01$ & $0.04 \pm 0.01$ & $0 \pm 0.0$ \\
$\mathrm{Zn}$ & $\mathrm{mg} / \mathrm{L}$ & $0.56 \pm 0.08$ & $0.04 \pm 0.0$ & $0.24 \pm 0.06$ \\
\hline
\end{tabular}

${ }^{\mathrm{a}}$ Adopted from Urum and Pekdemir (2004) 
expressed as the sum of all HMs, they were SAP, $2.02 \mathrm{mg} / \mathrm{L}$; TAN, $1.15 \mathrm{mg} / \mathrm{L}$; RAM, $0.95 \mathrm{mg} / \mathrm{L}$.

\section{Soil washing}

Both soils were washed in batch conditions. $1 \mathrm{~g}$ of contaminated soil $(\mathrm{m})$ was weighed and placed in $50 \mathrm{~mL}$ capacity polyethylene tubes, and then $40 \mathrm{~mL}$ of biosurfactant solution $(V)$ at a concentration of $3 \%$ was added. The samples were shaken at $150 \mathrm{rpm}$ at ambient temperature in a mechanical shaker for $24 \mathrm{~h}$. At the end of soil washing, the suspensions were centrifuged at $8000 \mathrm{rpm}$ for $20 \mathrm{~min}$ and the supernatants were filtered. In the liquid samples, the total HM concentrations were measured. In the solids previously dried at $60{ }^{\circ} \mathrm{C}, \mathrm{HM}$ fractions were determined.

In addition, sequential soil washing $\left(1^{\circ}\right.$ and $\left.2^{\circ}\right)$ was performed with the following combinations:

- the same class of biosurfactant in the $1^{\circ}$ and $2^{\circ}$ washings: SAP-SAP, TAN-TAN and RAM-RAM,

- different class of biosurfactant in the $1^{\circ}$ and $2^{\circ}$ washings: SAP-RAM and TAN-RAM.

The operational conditions ( $\mathrm{m} / \mathrm{V}$, biosurfactant concentration, washing time) were the same in the $1^{\circ}$ and $2^{\circ}$ soil washings.

\section{Analytical methods}

Soil texture was determined based on particle size distribution (Mastersizer 2000 laser particle size analyzer, Malvern Instruments, UK). The $\mathrm{pH}$ and electrical conductivity in soil were determined at 1:2.5 ratio (w/v) in $1 \mathrm{M} \mathrm{KCl}$ and distilled water extracts, respectively, using a pH-meter (HI 221) and a conductivity meter (HI 8733). In addition, the $\mathrm{pH}$ and electrical conductivity were measured directly in extracts after soil washing with biosurfactants.

Soil organic matter content was determined by sample combustion at $550{ }^{\circ} \mathrm{C}$ in a muffle furnace (Carbolite ESM9920). The cation exchange capacity (CEC) of the soils was assayed with Kappen's method (Ostrowska et al. 1991).

In the original SAP, TAN and RAM solutions, total organic carbon (TOC) was measured using a Shimadzu Liquid TOC-VCSN analyzer. Surface tension was measured using a K100 tensiometer (Krüss, Germany) employing the Wilhelmy plate method. Total HM concentrations in soil were determined with flame atomic absorption spectrometry (FAAS) (Varian, AA28OFS) after soil digestion in a mixture of $35-38 \% \mathrm{HCl}$ and $65 \% \mathrm{HNO}_{3}$ in a microwave oven (MARSXpress, CEM USA). Soil digestion was performed in polytetrafluoroethylene vessels with $1 \mathrm{~g}$ of dried soil (at $\left.105{ }^{\circ} \mathrm{C}\right), 9 \mathrm{~mL}$ of $\mathrm{HCl}$ and $3 \mathrm{~mL}$ of $\mathrm{HNO}_{3}$. A one-stage microwave program $\left(170{ }^{\circ} \mathrm{C}, 800 \mathrm{~W}, 30 \mathrm{~min}\right)$ was used.
After cooling, the extracts were filtered through Whatman 40 filter papers (pore size $8 \mu \mathrm{m}$ ) into 100 -mL glass flasks and filled to the mark with distilled water. In biosurfactant solutions and supernatants after soil washing, the HM concentrations were measured directly after sample dilution with distilled water.

For HM fractionation in soil, a modified BCR sequential extraction procedure was used (Pueyo et al. 2008). Four operationally defined fractions were determined for each HM using specific extracting agents and extraction conditions: $F 1$, exchangeable and acid soluble $(0.11 \mathrm{M}$ $\left.\mathrm{CH}_{3} \mathrm{COOH}, \mathrm{m} / \mathrm{V}=1 \mathrm{~g} / 40 \mathrm{~mL}, 16 \mathrm{~h}\right) ; F 2$, reducible $(0.5 \mathrm{M}$ $\left.\mathrm{NH}_{2} \mathrm{OH} \cdot \mathrm{HCl}, \mathrm{m} / \mathrm{V}=1 \mathrm{~g} / 40 \mathrm{~mL}, 16 \mathrm{~h}\right) ; F 3$, oxidizable $(30 \%$ $\mathrm{H}_{2} \mathrm{O}_{2}, \mathrm{~m} / \mathrm{V}=1 \mathrm{~g} / 10 \mathrm{~mL} ; \times 2$, water bath at $85{ }^{\circ} \mathrm{C} ; 1 \mathrm{M}$ $\mathrm{CH}_{3} \mathrm{COONH}_{4}, \mathrm{~m} / \mathrm{V}=1 \mathrm{~g} / 50 \mathrm{~mL}, 16 \mathrm{~h}$ ); and $F 4$, residual (using the same procedure as for total HMs).

All analyses were performed in triplicate. The accuracy and precision of total HM analysis using the FAAS method were checked using CRM 142 R reference material. The results of the BCR sequential extraction procedure were checked by comparing the sum of HM concentrations in the $F 1, F 2, F 3$ and $F 4$ fractions with the total HM concentration. The values of $\mathrm{Cd}, \mathrm{Cu}, \mathrm{Ni}, \mathrm{Pb}$ and $\mathrm{Zn}$ recovered were satisfactory, ranging from 92 to $107 \%$. TraceCERT ${ }^{\circledR} \mathrm{Cd}, \mathrm{Cu}, \mathrm{Ni}, \mathrm{Pb}$ and $\mathrm{Zn}$ standards for AAS (Fluka) were used for preparation of the calibration curves. The purity of the reagents was of analytical grade or better.

\section{Calculations}

Total HM concentration in soil/total HM concentration removed from soil (TM):

$\mathrm{TM}=\frac{\left(C_{\mathrm{L}} \times f\right)}{m} \times V$,

where $C_{\mathrm{L}}$ is the $\mathrm{HM}$ concentration in extract after soil digestion or in supernatant after soil washing $(\mathrm{mg} / \mathrm{L}), f$ is the dilution coefficient (-), $V$ is the volume of extract or supernatant $(\mathrm{L})$, and $m$ is the dry mass of soil $(\mathrm{kg})$.

Reduced partition index $\left(I_{\mathrm{R}}\right)$ to assess the stability of HMs in soil before and after soil washing (Gusiatin and Klimiuk 2012):

$I_{\mathrm{R}}=\frac{\sum_{i=1}^{k} i^{2} F_{i}}{k^{2}}$,

where $i$ is the index number of the extraction step, progressing from 1 (with the weakest extractant) to 4 (with the strongest extractant), $F_{\mathrm{i}}$ is the relative content of an $\mathrm{HM}$ in the $i$ th fraction (as a decimal value), and $k$ is the total number of $\mathrm{HM}$ fractions in the $\mathrm{BCR}$ procedure. 
The experiments were performed in triplicate to evaluate the reproducibility of the results. Differences between HM stabilities and removal of HMs with sequential soil washing were analyzed with Duncan's test with $p<0.05$ considered significant. Cluster analysis (CA) was used to separate the HMs in soils into meaningful groups (clusters) based on their $I_{\mathrm{R}}$ before and after a single soil washing. All statistical analyses were performed using Statistica 13.1 (Dell, Inc.).

\section{Results and discussion}

\section{HM distributions in soils}

The distributions of HMs as determined with the modified BCR procedure are shown in Fig. 1. The HMs had different distribution patterns in soil 1 and soil 2. In soil 1, the content of all HMs was lower in the exchangeable fraction $(F 1)$ and higher in the reducible $(F 2)$ and oxidizable $(F 3)$ fractions than in these fractions in soil 2. Although HMs at low concentrations are usually more strongly bound to soil than HMs at high concentrations (Han et al. 2003), this was not the case in the present study: the HMs in soil 1, which were present at higher concentrations, were more strongly bound than those in soil 2 . This was confirmed by the values of the reduced partition index $\left(I_{\mathrm{R}}\right)$ (Fig. 1). The differences in HM distributions and their bonding strength are caused by two factors: soil properties and soil aging. Firstly, soil 1 contained more organic matter than soil 2 (Table 1), which facilitated greater HM distribution into the oxidizable (F3) fraction. Moreover, soil 2 was alkaline (Table 1), which facilitated HM distribution into carbonates, increasing their content in the $F 1$ fraction. Secondly, the length of time that the soils were aged after spiking was different, i.e., 24 months for soil 1 and only 1 month for soil 2 . With aging time, HMs slowly redistribute into more stable fractions.

$\mathrm{Cd}$ is highly mobile because it has a high affinity with carbonates and may coprecipitate with carbonate minerals. Tang et al. found that, although soils spiked with different concentrations of Cd $(48.2-813 \mathrm{mg} / \mathrm{kg})$ had been aged for 3 years, the percentages of total $\mathrm{Cd}$ in the $F 1$ and $F 2$ fractions were still very high, with a mean value of $98 \%$ (Tang et al. 2018). In the present study, the total percent content of $\mathrm{Cd}$ in these two fractions was the same. Ghayoraneh and Qishlaqi (2017) found that $70 \%$ of total Cd in soils from around a $\mathrm{Zn} / \mathrm{Pb}$ smelter (northwest Iran) was in the $F 1$ and $F 2$ fractions. Those authors wrote that increasing the $\mathrm{pH}$ of soil rich in $\mathrm{Fe}-\mathrm{Mn}$ oxides and clay minerals increases the content of $\mathrm{Cd}$ in the $\mathrm{F} 2$ fraction, whereas decreasing the $\mathrm{pH}$ increases its content in the $F 1$ fraction. In the present study, however, the soil aged for 24 months at $\mathrm{pH} 5.9$ had a lower content of $\mathrm{Cd}$ in the $F 1$ fraction than the soil aged 1 month at $\mathrm{pH}$ 7.7. This indicates that the difference in soil aging times had a greater influence on Cd distribution than the difference in soil $\mathrm{pH}$.

In the case of $\mathrm{Zn}$ in soil 1 , more was present in the $F 2$ fraction than the $F 1$ fraction. Sorption of $\mathrm{Zn}$ onto $\mathrm{Fe}-\mathrm{Mn}$ oxides is probably the most important of the factors that influence its distribution in soil (Kabala and Singh 2001). In contrast, in soil $2, \mathrm{Zn}$ was predominantly in the $F 1$ fraction. In alkaline soils, $\mathrm{Zn}$ is associated with carbonates $\left(\mathrm{ZnCO}_{3}\right)$ (Ghayoraneh and Qishlaqi 2017).

As with $\mathrm{Cd}$ and $\mathrm{Zn}$, the percent content of $\mathrm{Ni}$ in the $F 1$ fraction was relatively high. Tewari et al. (2010) reported that the addition of soluble $\mathrm{Ni}$ (as an inorganic salt) increased its content in the $F 1$ and $F 2$ fractions in acidic soil; in the $F 1, F 2$ and $F 4$ fractions in neutral soil; and in the $F 2$ and $F 4$ fractions in alkaline soil. In spiked soil cultivated for 3 years, Ni content in the $F 1$ fraction was still high (60\% of $100 \mathrm{mg} / \mathrm{kg}$ ) (Kuziemska et al. 2014).

$\mathrm{Cu}$ is specifically adsorbed or fixed in soils and, thus, has lower mobility than other HMs (Alloway 1995). In soil 1 , which had a higher organic matter content, the percent content of $\mathrm{Cu}$ in the $\mathrm{F} 3$ fraction was higher than that in soil $2(10.1 \%$ vs. $4.8 \%$ of total $\mathrm{Cu})$, which had a shorter aging time and lower organic matter content (4.0\%). This can be attributed to the high constant of complexation between $\mathrm{Cu}$ and soil organic matter, as the HM forms strong associations with oxygen and sulfur atoms on the surface of organic matter (Evans 1989). In addition, $\mathrm{Cu}$ had the largest percent content in the $F 4$ fraction of all the HMs. This is due to the fact that $\mathrm{Cu}$ is easily chemisorbed on or incorporated in clay minerals (Ghayoraneh and Qishlaqi 2017).

The majority of $\mathrm{Pb}$ was associated with $\mathrm{Fe}-\mathrm{Mn}$ oxides. $\mathrm{Pb}$ has a very strong affinity for $\mathrm{Fe}-\mathrm{Mn}$ oxides and, as a result, inner sphere sorption complexes are formed (Scheinost et al. 2001). Thus, in the present study, $\mathrm{Pb}$ had the smallest changes in distribution between soils, despite the differences in total $\mathrm{Pb}$ concentrations and aging times. Similarly, Kulikowska et al. (2015) did not observe significant changes in the content of $\mathrm{Pb}$ in the reducible fraction as aging time increased from 1 to 24 months (83\% of total $\mathrm{Pb}$ in this fraction after aging for 1 month, and $82 \%$ after aging for 12 and 24 months). Moreover, Ghayoraneh and Qishlaqi (2017) reported that the distribution pattern of $\mathrm{Pb}$ in soil was similar, with the largest share in the reducible fraction, regardless of the source of the $\mathrm{Pb}$ (native or anthropogenic).

Because HMs in the $F 1$ fraction are loosely bound to soil and they can be bioavailable and highly toxic, the content of HMs in this fraction determines their mobility. Thus, the most mobile HMs in both soils were $\mathrm{Cd}$, $\mathrm{Zn}$ and $\mathrm{Ni}$. In contrast, the least mobile $\mathrm{HMs}$ were $\mathrm{Cu}$ and $\mathrm{Pb}$. The fraction with the second highest content of HMs was the $F 2$ fraction, which contained $80-85 \%$ of the $\mathrm{Pb}, 54-61 \%$ of the $\mathrm{Cu}, 29-51 \%$ of the $\mathrm{Ni}, 29-48 \%$ of the $\mathrm{Zn}$ and $22-37 \%$ of the $\mathrm{Cd}$ in each soil. $\mathrm{Cu}$ and $\mathrm{Ni}$ had 
Cd

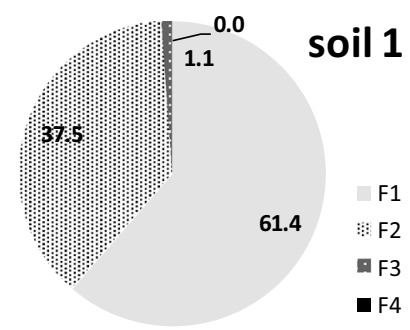

$\mathrm{Cu}$

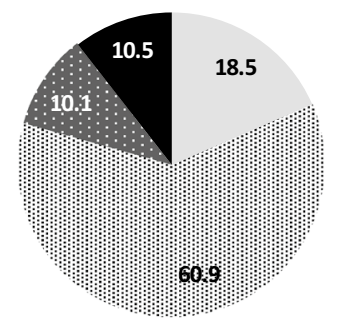

$\mathrm{Ni}$

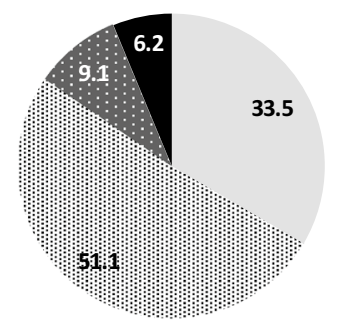

$\mathrm{Pb}$

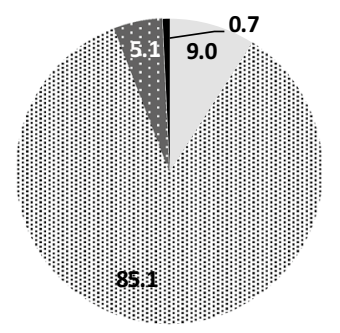

$\mathrm{Zn}$

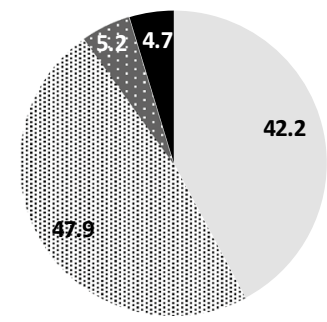

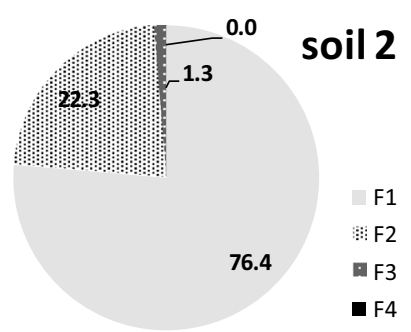
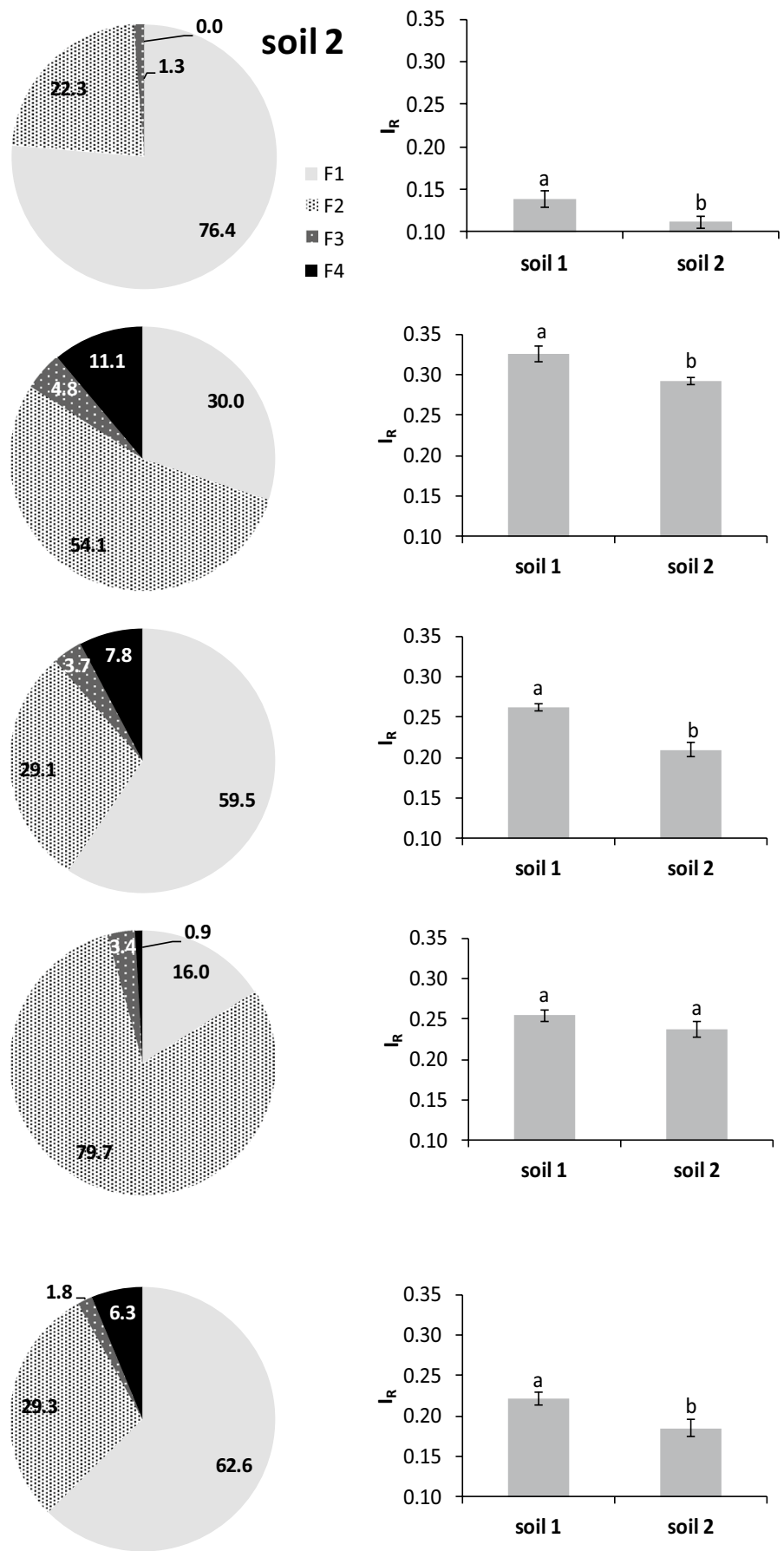

Fig. $1 \mathrm{HM}$ distribution in contaminated soils (as \% content of individual fractions) and their stability (as reduced partition index, $I_{\mathrm{R}}$ ). For each $\mathrm{HM}$, values of $I_{\mathrm{R}}$ under the same letters do not differ significantly at $p<0.05$

the highest percent content in the $F 3$ fraction, and their content in this fraction was higher in soil 1 than in soil 2. The percent content of HMs in the F4 fraction was not high, with $\mathrm{Cu}, \mathrm{Ni}$ and $\mathrm{Zn}$ having the highest content in this fraction. Low levels of HMs in the $F 4$ fraction are typical of anthropogenic contamination of soil. Based on the $I_{\mathrm{R}}$ values, the rankings of HM stabilities in both soils 
were nearly the same: $\mathrm{Cu}>\mathrm{Ni} \approx \mathrm{Pb}>\mathrm{Zn}>\mathrm{Cd}$ (soil 1) and $\mathrm{Cu}>\mathrm{Pb}>\mathrm{Ni}>\mathrm{Zn}>\mathrm{Cd}$ (soil 2).

\section{The effect of single soil washing with biosurfactants on HM removal}

In Fig. 2, the efficiency of HM removal with SAP, TAN and RAM in relation to HM stability in soil (as $I_{\mathrm{R}}$ ) is shown. Theoretically, an HM with a lower $I_{\mathrm{R}}$ should be removed more efficiently than one with a higher $I_{\mathrm{R}}$. In the present study, this relationship was true for a given HM in different soils, but not for different HMs in the same soil. This suggests that removal of multi-HMs from a given soil was affected by factors other than just their stability (based on the $I_{\mathrm{R}}$ ).

The results clearly indicate that the removal of HMs varied depending on the type of HM, its concentration in soil, and the class of biosurfactant used for soil washing. All HMs were more efficiently removed from soil 2, which had a lower total HM concentration and lower $I_{R}$, than from soil 1 , irrespective of the kind of biosurfactant that was used.
$\mathrm{Zn}$ removal differed the most between soils, with $23.4 \%$, $28.8 \%$ and $22.5 \%$ more removed from soil 2 than soil 1 with SAP, TAN and RAM, respectively. Regardless of the concentration of $\mathrm{Pb}$ in soil, SAP and TAN removed this HM less effectively than RAM. In more contaminated soil, SAP was the most effective for $\mathrm{Cd}, \mathrm{Ni}$ and $\mathrm{Cu}$ removal, while TAN was most effective for removal of all HMs, except for $\mathrm{Pb}$. In the soil with the lower HM concentrations, both plant biosurfactants also effectively removed $\mathrm{Zn}$. In contrast, RAM effectively removed $\mathrm{Cd}$ and $\mathrm{Pb}$ but was less effective for $\mathrm{Cu}$ and Ni removal than TAN and SAP. RAM removed $\mathrm{Zn}$ from both soils with lower or similar efficiencies to SAP and TAN, respectively. The efficiency of $\mathrm{Pb}$ removal with RAM was 2.3-4.5 times higher than removal of this HM with SAP and 0.8-4.5 times higher than its removal with TAN. In terms of the efficiency of removal of individual HMs, the biosurfactants can be ranked in the following order: for $\mathrm{Cd}$ in both soils and $\mathrm{Pb}$ in soil $1, \mathrm{RAM}>\mathrm{SAP}>\mathrm{TAN}$; for $\mathrm{Pb}$ in soil 2, RAM $>$ TAN $>$ SAP; for $\mathrm{Cu}$ and Ni in both soils, SAP $>$ TAN $>$ RAM; for Zn in soil 1 , SAP $>$ TAN $\approx$ RAM; and for $\mathrm{Zn}$ in soil 2, SAP $>$ TAN $>$ RAM.
Fig. 2 Efficiency of HM removal from soils with biosurfactants as a function of $\mathrm{HM}$ stability in soil $\left(I_{\mathrm{R}}\right)$ : a, b SAP; c, d TA; e, f RAM (a)

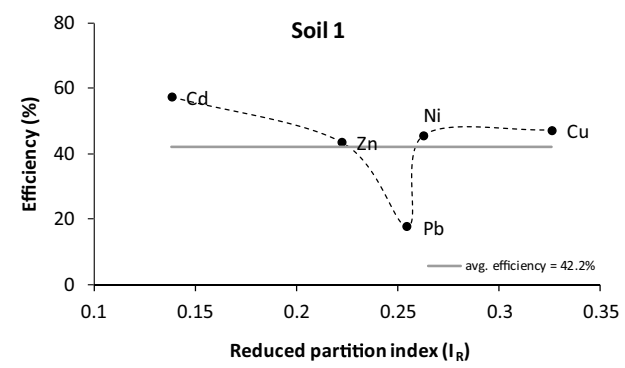

(c)

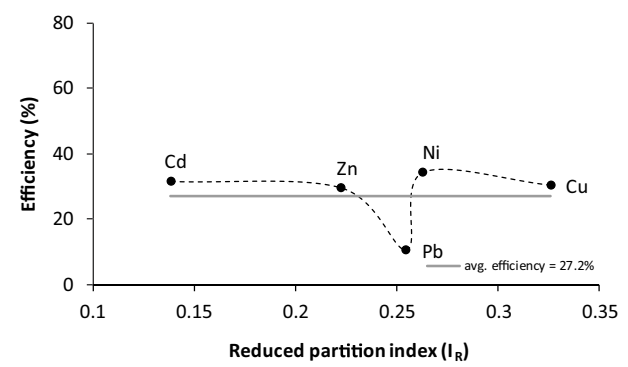

(e)

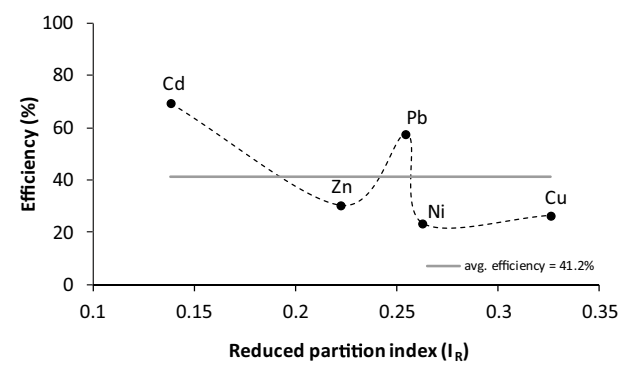

(b)

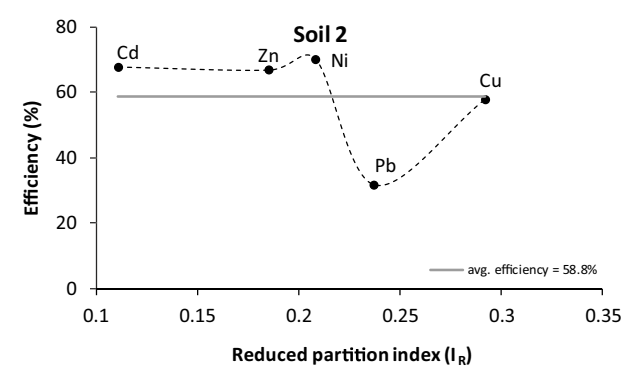

(d)

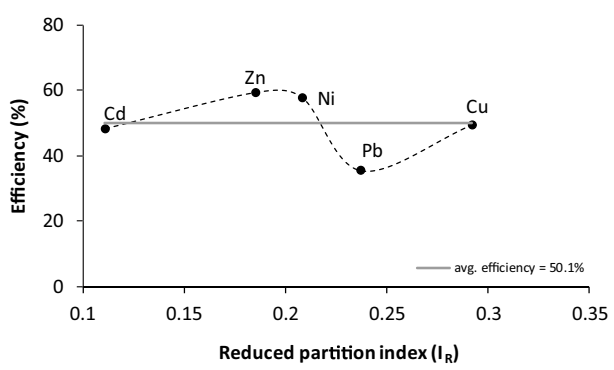

(f)

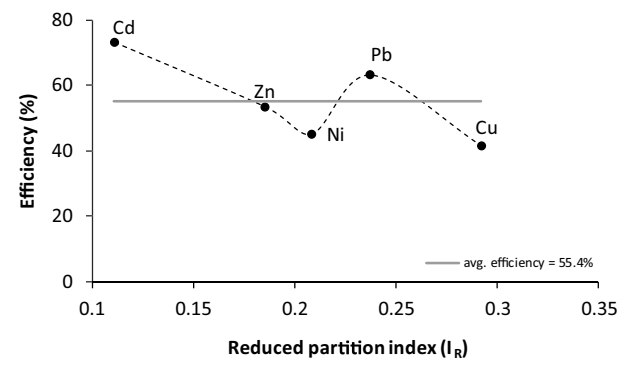


In the present study on soil contaminated with multi$\mathrm{HMs}$, RAM removed $\mathrm{Cd}$ and $\mathrm{Pb}$ more effectively than the other HMs. Anionic RAM with a negative charge (from a dissociated carboxyl group in micelles) can form ionic bonds with HMs, creating stabilizing forces in the RAM-HM complex that are stronger than those in the HM-soil complex (Açıkel 2011). Wan et al. (2015) found that Pb can be complexed more readily with RAM than Cd.

Slizovskiy et al. (2011) found that the effectiveness of RAM in removal of HMs from soil decreased in the following order: $\mathrm{Pb}(68 \%)>\mathrm{Cu}(56 \%)>\mathrm{Cd}(43 \%)>\mathrm{Zn}$ (39\%). Juwarkar et al. (2008) used RAM synthesized from distillery wastewater by $P$. aeruginosa $\mathrm{BS} 2$ and found that the effectiveness of HM removal was as follows: $\mathrm{Cd}=\mathrm{Cr}>\mathrm{Pb}=\mathrm{Cu}>\mathrm{Ni}$. This can be attributed to the fact that the stability constants of RAM complexes with $\mathrm{Cu}, \mathrm{Pb}$ and $\mathrm{Cd}$ are higher than those of its complexes with $\mathrm{Zn}$ and $\mathrm{Ni}$ (Ochoa-Loza et al. 2001). Although RAM-Cu complexes have a high stability constant, $\mathrm{Cu}$ removal from both soils in the present study was much lower than $\mathrm{Pb}$ and Cd removal, which is in agreement with previous studies that have shown a high affinity of RAM for $\mathrm{Pb}$ and $\mathrm{Cd}$. The relatively low $\mathrm{Cu}$ removal may be due to the presence of other HMs, particularly $\mathrm{Pb}$, at higher total concentrations than $\mathrm{Cu}$. The efficiency of $\mathrm{Cu}$ removal with RAM can be high when soil is not co-contaminated with other HMs. Venkatesh and Vedaraman applied a 2\% RAM solution to soil spiked with only $\mathrm{Cu}$ and were able to remove $74 \%$ of the HM, even though its initial concentration was nearly $5000 \mathrm{mg} / \mathrm{kg}$ (Venkatesh and Vedaraman 2012).

SAP and TAN were less effective at removing $\mathrm{Pb}$ than RAM, but with regard to removing the other HMs, SAP and TAN were either more effective, or similar in effectiveness to RAM. The effectiveness of the plant biosurfactants differed more with soil 1 (more contaminated) than soil 2 (less contaminated). Overall, SAP was more effective than TAN for removal of $\mathrm{Cd}, \mathrm{Cu}, \mathrm{Ni}, \mathrm{Zn}$, but less effective for removal of $\mathrm{Pb}$, especially in soil 2 . TAN is phenolic organic acid with numerous hydroxyl groups associated with the aromatic ring, forming a trihydroxy-benzoic structure. With phenolic compounds like TAN, the presence of suitably oriented hydroxyl groups in the structure of the ligand can be essential for the formation of complexes between the phenolic groups and HMs (Karamać and Karamać 2009).

The ability of SAP to remove more HMs than TAN is related to the content of carboxylic groups in the two substances, with more than ten times more carboxylic groups in SAP than TAN (Gusiatin 2014). SAP can remove a large amount of $\mathrm{Cd}$ from soils because it contains an exchangeable secondary $\mathrm{H}^{+}$cation that can be exchanged for $\mathrm{HM}$ cations (Hong et al. 2002). Thus, these $\mathrm{H}^{+}$cations were easily exchanged with HMs that had a high share in the mobile fraction, i.e., $\mathrm{Cd}, \mathrm{Ni}, \mathrm{Zn}$, which was especially noticeable in soil 2 . In soil 1 , the share of $\mathrm{Pb}$ in the mobile fraction was the lowest, so SAP and TAN removed less of this HM than of the others. In addition, an excessive concentration SAP could have led to the formation of $\mathrm{Pb}$ precipitates and decreased the removal of this HM (Zhang et al. 2018).

Zhan et al. (2012) stated that SAP can effectively remove HMs from soil at concentrations far above its critical micelle concentration (CMC) of $0.1 \%$. In the present study, at $3 \% \mathrm{SAP}$, the effectiveness of $\mathrm{Cu}, \mathrm{Cd}, \mathrm{Pb}$, and $\mathrm{Zn}$ removal was $44 \%, 95 \%, 83 \%$, and $20 \%$, respectively. The effectiveness of $\mathrm{Pb}$ removal was higher in Zhan et al. (2012) than in the present study due to the lower Pb content $(179.0 \mathrm{mg} / \mathrm{kg}))$ and to soil properties that improved soil washing performance in their study, i.e., a low CEC $(5.7 \mathrm{cmol} / \mathrm{kg})$ and a low organic matter content $(1.3 \%)$. They reported that the mechanisms involved in HM removal with SAP were not only ion exchange, but also micelle formation and complexation of HMs with carboxyl groups (Zhan et al. 2012).

In the present study, all biosurfactants were used at concentrations above their CMC, which means that micelles were responsible for HM removal. When biosurfactant concentrations are above the $\mathrm{CMC}$, the proposed mechanism of HM removal from soil includes several steps (Chen et al. 2008; Tang et al. 2017). First, under the conditions of reduced interfacial tension that are present above the CMC, biosurfactant molecules from dissociated micelles can readily adsorb at a soil-water interface. At this stage, the biosurfactant hydrophilic anions interact with cationic HMs, while the nonionic hydrophilic polar groups of the biosurfactants may react with soil constituents. As a result, a monolayer of biosurfactant coverage is achieved. The adsorbing biosurfactant molecules continually form ion pairs with HM ions in a head-tohead and tail-to-tail fashion, mainly by ion exchange of $\mathrm{H}^{+}$cations between HMs in soil and biosurfactants and HM complexation with carboxyl and hydroxyl groups of biosurfactants. Because, the interfacial tension of biosurfactants is lowest at concentrations above $\mathrm{CMC}$, the formation of HM-biosurfactant complexes is facilitated by reduced adhesion between HM and soil particles. Next, orientational rearrangement of biosurfactant molecules at the soil-water interface leads to self-assembly of HMbiosurfactant complexes by aggregation of hemimicelles on the top of the monolayer. Finally, micellar HM-biosurfactant complexes are desorbed into bulk solution (Chen et al. 2008). Under conditions of reduced biosurfactant surface tension, micellar HM-biosurfactant complexes are easily released into solution, and their re-adsorption in soil is prevented. In this study, although all the biosurfactants effectively reduced surface and interfacial tension (Table 2), their ability to remove individual HMs differed. 


\section{The effect of single washing with biosurfactants on HM distributions and their stability in soils}

In the present study, the effectiveness of the biosurfactants for HM removal was analyzed based on the changes in the concentrations of HMs in the fractions. The fractions were grouped according to the BCR procedure, based on the availability of the HMs in that fraction: ready available (RA) comprises only the $F 1$ fraction; potentially labile (PL) consists of the $F 2$ and $F 3$ fractions, whose mobility can increase when soil properties ( $\mathrm{pH}$, redox) change; and non-available (NA) comprises only the $F 4$ fraction, in which HMs are strongly bound to the crystalline structures of minerals in soil matrices (Cao et al. 2018).

The tested biosurfactants removed HMs more effectively from the RA fraction than from the PL and NA fractions in both the soil with high HM concentrations and the soil with low HM concentrations. RAM were more effective than the other two washing agents for removing $\mathrm{Cd}$ from the RA and PL fractions in both soils. As a result, RAM removed Cd with the highest efficiency (Fig. 2). In contrast to washing with SAP and RAM, washing with TAN caused the $\mathrm{Cd}$ concentration in the PL fraction in washed soil to be higher than that in unwashed soil. This suggests that, during soil washing with TAN, Cd is partially redistributed from the $F 1$ to the $F 2$ fraction. Wan et al. found that a $1 \%$ RAM solution removed Cd from the RA fraction in soil cocontaminated with $\mathrm{Pb}$ and lindane with an efficiency of $75 \%$ (Wan et al. 2015). Hong et al. (2002) found that, in soils containing 701-1484 mg/kg of Cd, most of which was in the RA fraction, 3\% SAP almost completely removed $\mathrm{Cd}$ from that fraction. Zhan et al. (2012) confirmed that SAP decreased $\mathrm{Cd}$ content in RA in soil below detection limits, whereas it decreased $\mathrm{Cd}$ content in the PL fraction more efficiently (> 80\%) than in the present study (by 25-36\%). In the present study, Cd was not found in the NA fraction in soils either before or after washing with biosurfactants (Fig. 3a, b). Although TAN had acidic pH, it removed $\mathrm{Cd}$ from the RA fraction less effectively than SAP, especially in soil 1 . This can be attributed to the stronger affinity of TAN for other HMs (e.g., $\mathrm{Pb}$ ), which were present at higher concentrations.

In soil $1, \mathrm{SAP}$ and RAM removed $\mathrm{Cu}$ from the RA fraction more effectively than TAN, whereas in soil 2 , SAP and TAN removed the most $\mathrm{Cu}$ from this fraction (117 and $119 \mathrm{mg} / \mathrm{kg}$, respectively) (Fig. 3c, d). In both soils, SAP decreased the $\mathrm{Cu}$ concentration in the $F 2$ and $F 3$ fractions (i.e., the PL fraction) more than TAN and RAM did. The large amount of $\mathrm{Cu}$ removed from these two fractions with SAP was the reason why total $\mathrm{Cu}$ removal from both soils with SAP was so high. Gusiatin and Klimiuk (2012) reported that $3 \%$ SAP efficiently removed $\mathrm{Cu}$ from the $F 1$ and $F 2$ fractions, and even from the $F 3$ fraction in soils that differed in texture (loamy sand, loam and silty clay). Gusiatin et al. (2014) observed that SAP and TAN removed $\mathrm{Cu}$ with similar efficiency from the $F 1$ fraction in industrial soil co-contaminated with $\mathrm{Cu}, \mathrm{Pb}$ and $\mathrm{Zn}$; however, SAP removed substantially more $\mathrm{Cu}$ from the $F 2$ fraction in this soil than TAN did.

SAP was the most efficient biosurfactant for removing Ni from the RA and PL fractions in both soils and, thus, had the highest efficiency of total Ni removal of the three biosurfactants (Fig. 2). In the soil with the higher total Ni content, RAM only removed Ni from the RA fraction, whereas in the soil with the lower total Ni content, RAM also partially removed $\mathrm{Ni}$ from the PL fraction. Of the three biosurfactants, TAN was the least efficient at removing $\mathrm{Ni}$ from the RA fraction in soil 1 and from the PL fraction in soil 2 (Fig. 3e, f).

It is worth mentioning that all three biosurfactants almost completely removed $\mathrm{Pb}$ from the RA fraction (Fig. $3 \mathrm{~g}$, h). However, the biosurfactants differed in their ability to remove $\mathrm{Pb}$ from the PL fraction. Soil washing with RAM decreased the $\mathrm{Pb}$ concentration in the PL fraction by $55 \%$ (soil 1) and 59\% (soil 2). In contrast, SAP and TAN decreased the $\mathrm{Pb}$ concentration in the PL fraction in soil 1 by 13 and 5\%, respectively, and they decreased the $\mathrm{Pb}$ concentration in this fraction in soil 2 by 23 and 26\%, respectively. These decreases in $\mathrm{Pb}$ content in the PL fraction are due to removal of $\mathrm{Pb}$ from iron oxides and the results suggest that RAM more effectively releases $\mathrm{Pb}$ from these oxides than plant biosurfactants. Akintunde et al. (2015) confirmed that the Fe concentration in soil was decreased about $60 \%$ by RAM. Neilson et al. (2003) found that, although RAM did not effectively remove $\mathrm{Pb}$ from heavily contaminated (3780-23,900 mg/kg) aged soils, they were more effective than carboxymethyl-beta-cyclodextrin for removing $\mathrm{Pb}$ bound to amorphous iron oxides. In the present study, SAP showed little ability to remove $\mathrm{Pb}$ from the reducible fraction. These results are similar to those of previous studies. Deng et al. (2015) reported that carbonate-bound, organicsbound and sulfide-residual $\mathrm{Pb}$ could be effectively removed from soil by SAP. Gusiatin et al. (2014) found that less than $10 \%$ of $\mathrm{Pb}$ in the $F 2$ fraction was removed with a $3 \%$ SAP solution. Hong et al. (2002) also used SAP and observed that $\mathrm{Pb}$ was more efficiently removed from the exchangeable and carbonate fractions than from the $\mathrm{Fe}-\mathrm{Mn}$ oxide and organic fractions. RAM and SAP may differ in their ability to remove $\mathrm{Pb}$ because the biosurfactants differ in their ability to form complexes with the HM, as the stability constant $(\log K)$ of $\mathrm{Pb}$-SAP chelate in aqueous solution is lower $(\log K[\mathrm{~Pb}]=3.91)$ than that of Pb-RAM chelate $(\log$ $K[\mathrm{~Pb}]=8.58)$ (Ochoa-Loza et al. 2001; Tang et al. 2017).

In the present study, TAN removed $\mathrm{Pb}$ much less effectively than in Gusiatin et al. (2014). This difference may be due to the conditions in the previous study, in which the $\mathrm{pH}$ 
Fig. 3 Concentrations of

HMs in ready available (RA), potentially labile (PL) and nonavailable (NA) fractions in soils before and after single washing with biosurfactants: a, b Cd, c, $\mathbf{d ~ C u}, \mathbf{e}, \mathbf{f ~ N i}$. RA indicates the exchangeable and acid soluble fraction, the PL fraction comprises the reducible $(F 2)$ and organic (F3) fractions (indicated in black), and NA indicates the residual fraction (a)

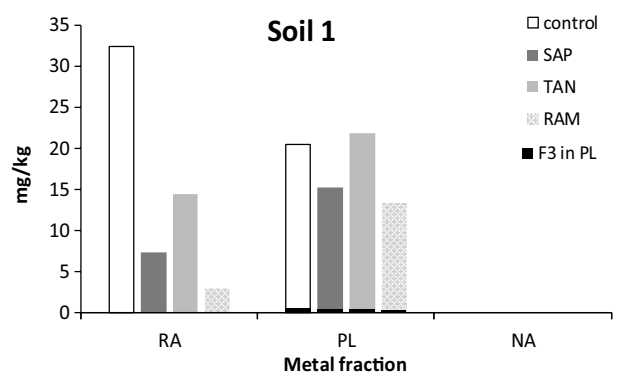

(c)

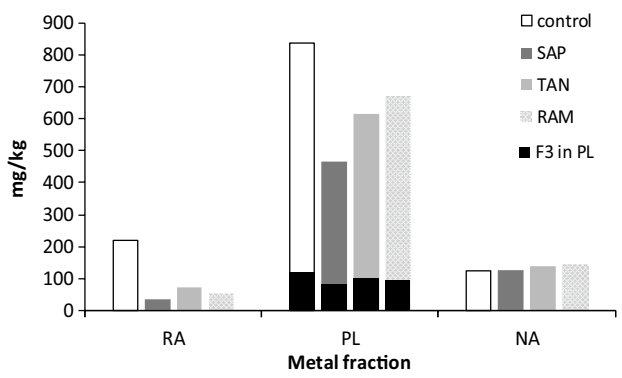

(e)

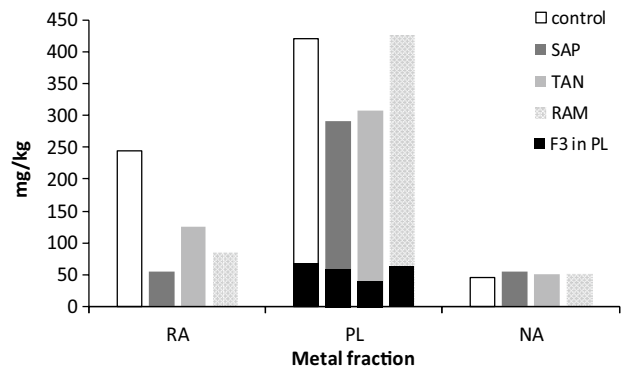

(g)

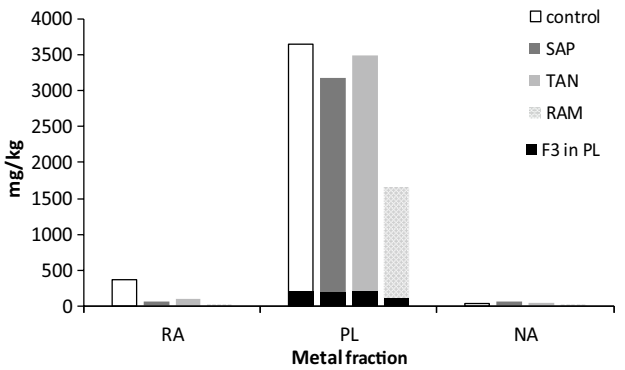

(i)

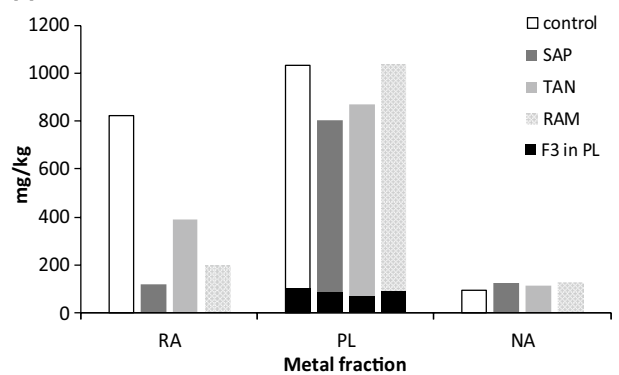

(b)

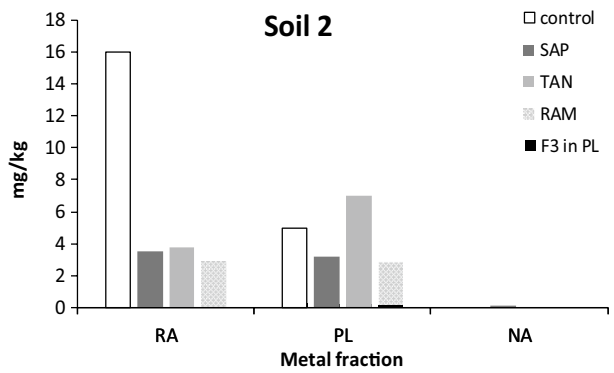

(d)

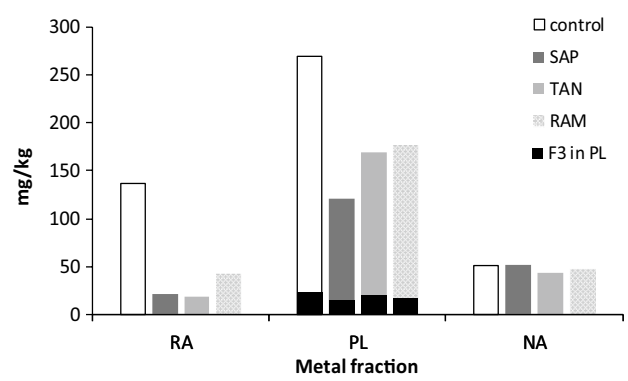

(f)

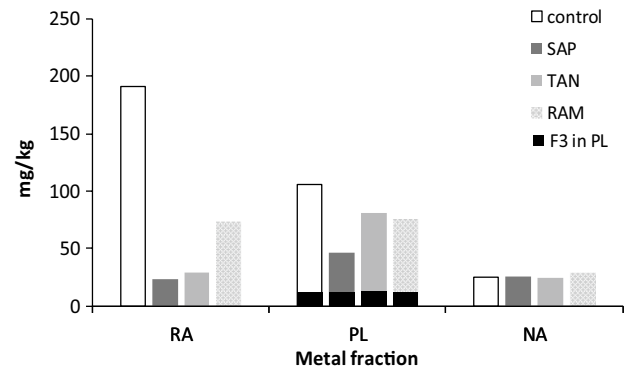

(h)

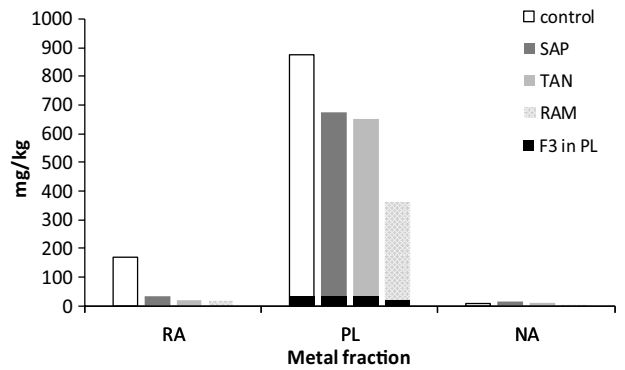

(j)

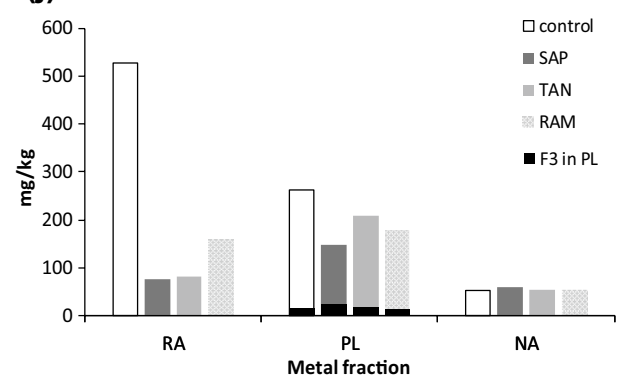


of the washing solution was lower than that in the present study (3.44 vs. 4.24), and the soil had a very low organic matter content $(0.21 \%)$ and a low cation exchange capacity $(15 \mathrm{cmol} / \mathrm{kg})$. In the present study, although the total concentrations of $\mathrm{Zn}$ and Ni differed, they had similar distribution patterns (Fig. 1). For this reason, removal of these HMs from the RA and PL fractions proceeded in a similar fashion. Except for $\mathrm{Cd}$, the investigated HMs could not be removed from the NA fraction during a single washing with the tested biosurfactants. In fact, the concentrations of $\mathrm{Ni}, \mathrm{Pb}$ and $\mathrm{Zn}$ in the NA fraction increased slightly during washing with SAP, and the concentrations of $\mathrm{Cu}, \mathrm{Ni}, \mathrm{Pb}$ and $\mathrm{Zn}$ in this fraction increased during washing with TAN and RAM.

As shown in Fig. 4, soil washing with SAP, TAN and RAM significantly increased the stability of all the HMs in the soils $(p<0.05)$. This increase was due to effective HM removal from the RA fraction, partial removal from the $F 2$ fraction (part of the PL fraction), minimal changes in HM concentration in the $F 3$ fraction, and some increase in HM concentration in the $F 4$ fraction, which is the most important with regard to the stability of HMs. The stability of most of the HMs increased more in soil 2 than in soil 1, which had higher total concentrations of the HMs. In both soils, the increase in $\mathrm{Cu}, \mathrm{Ni}$ and $\mathrm{Zn}$ stability was greater than that of the other HMs, and SAP increased the stability of $\mathrm{Cu}, \mathrm{Ni}$ and Zn more than TAN and RAM did.

Hierarchical cluster analysis also indicated that SAP, TAN and RAM affected HM stability (Fig. 5). Dendrograms were created on the basis of the $I_{\mathrm{R}}$ of the HMs, and these dendrograms differed between washed and unwashed soils. In unwashed soil 1, the HMs were grouped into one cluster ( $\mathrm{Pb}$ and $\mathrm{Ni}$ ) and three singletons ( $\mathrm{Zn}, \mathrm{Cu}$ and $\mathrm{Cd}$ ). The smaller distance between the members of the cluster reflects the fact that, although the fractionation of $\mathrm{Pb}$ and Ni differed somewhat, they had similar stability. After soil 1 was washed with biosurfactants, $\mathrm{Zn}, \mathrm{Ni}$ and $\mathrm{Pb}$ showed the greatest changes in stability. After washing this soil with SAP or RAM, Zn and Ni were most similar in terms of stability; after washing this soil with TAN, $\mathrm{Zn}$ and $\mathrm{Pb}$ were most similar (Fig. 5a). In unwashed soil 2, in contrast, Zn and $\mathrm{Ni}$ were grouped into a cluster, and $\mathrm{Pb}, \mathrm{Cu}$ and $\mathrm{Cd}$ were in singletons. After washing soil 2 with SAP or TAN, Ni and
Fig. 4 The effect of single soil washing with SAP, TAN and RAM on HM stability (as $I_{\mathrm{R}}$ ): a $\mathrm{Cd}, \mathbf{b} \mathrm{Cu}, \mathbf{c} \mathrm{Ni}, \mathbf{d ~ P b}$, e Zn. Values of $I_{\mathrm{R}}$ followed by the same letters do not differ significantly at $p<0.05$ (a)

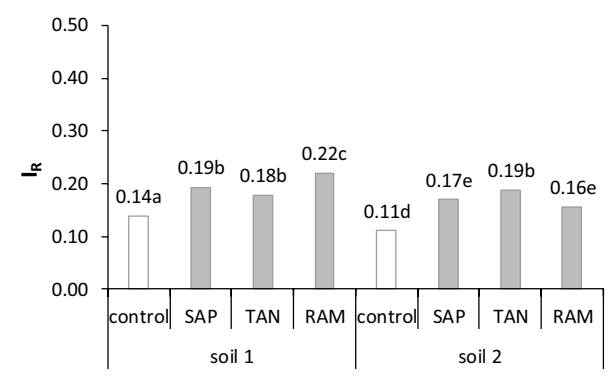

(c)

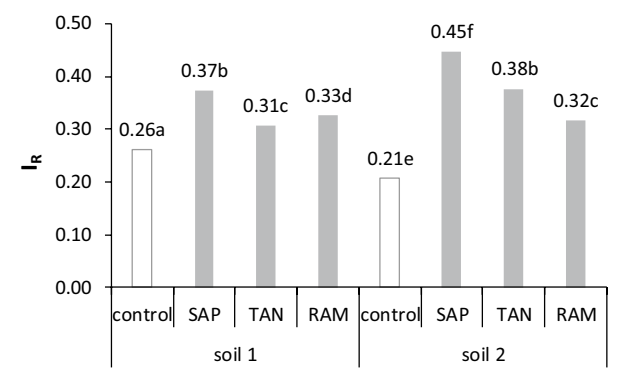

(e)

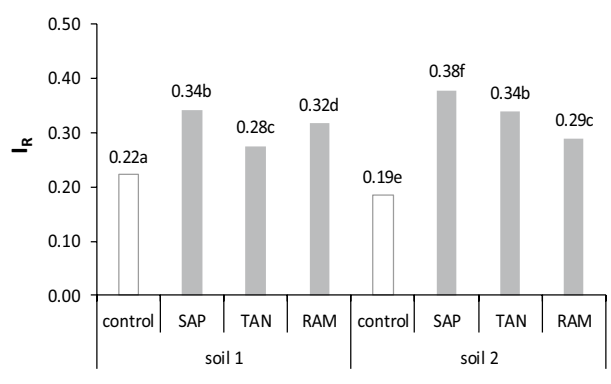

(b)

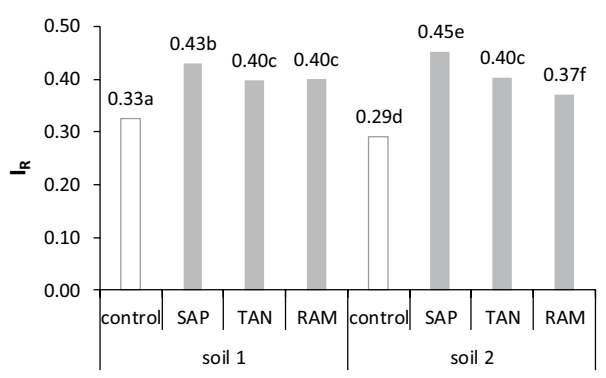

(d)

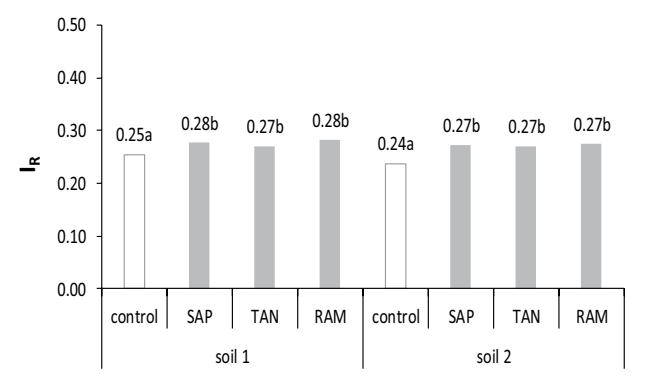



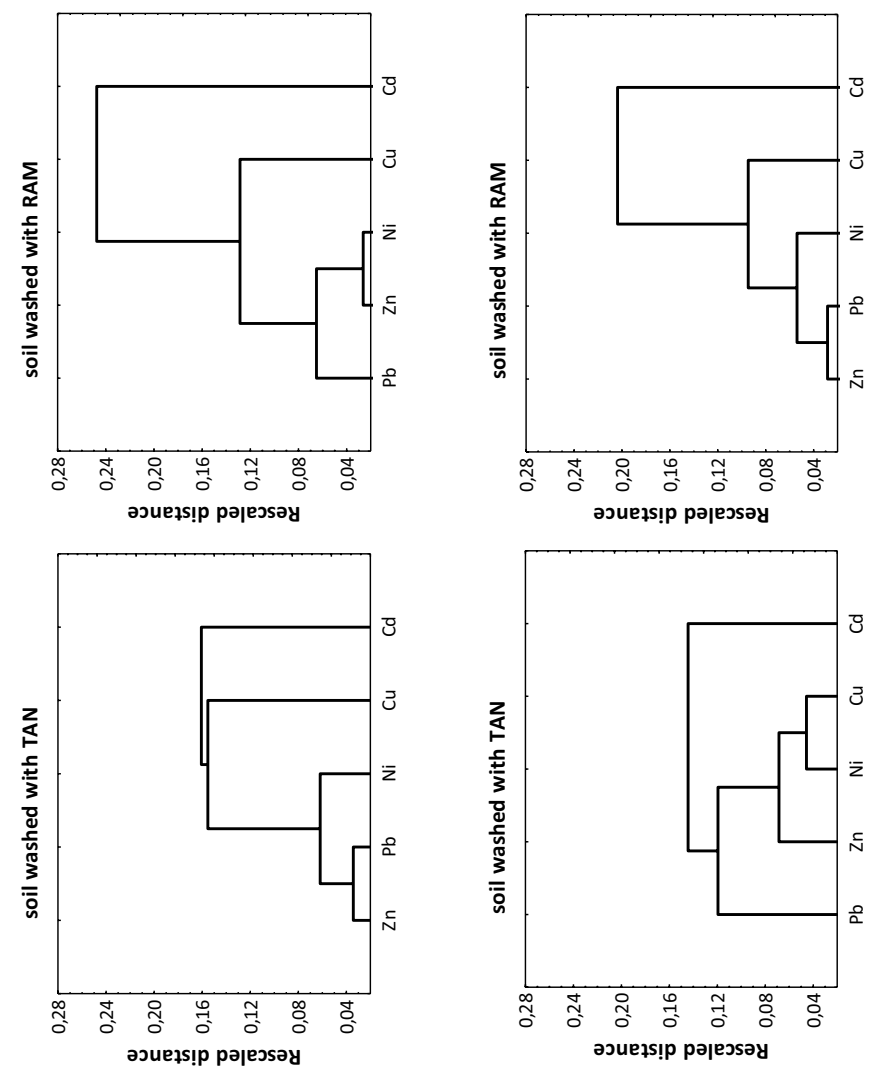

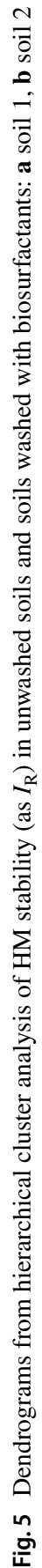
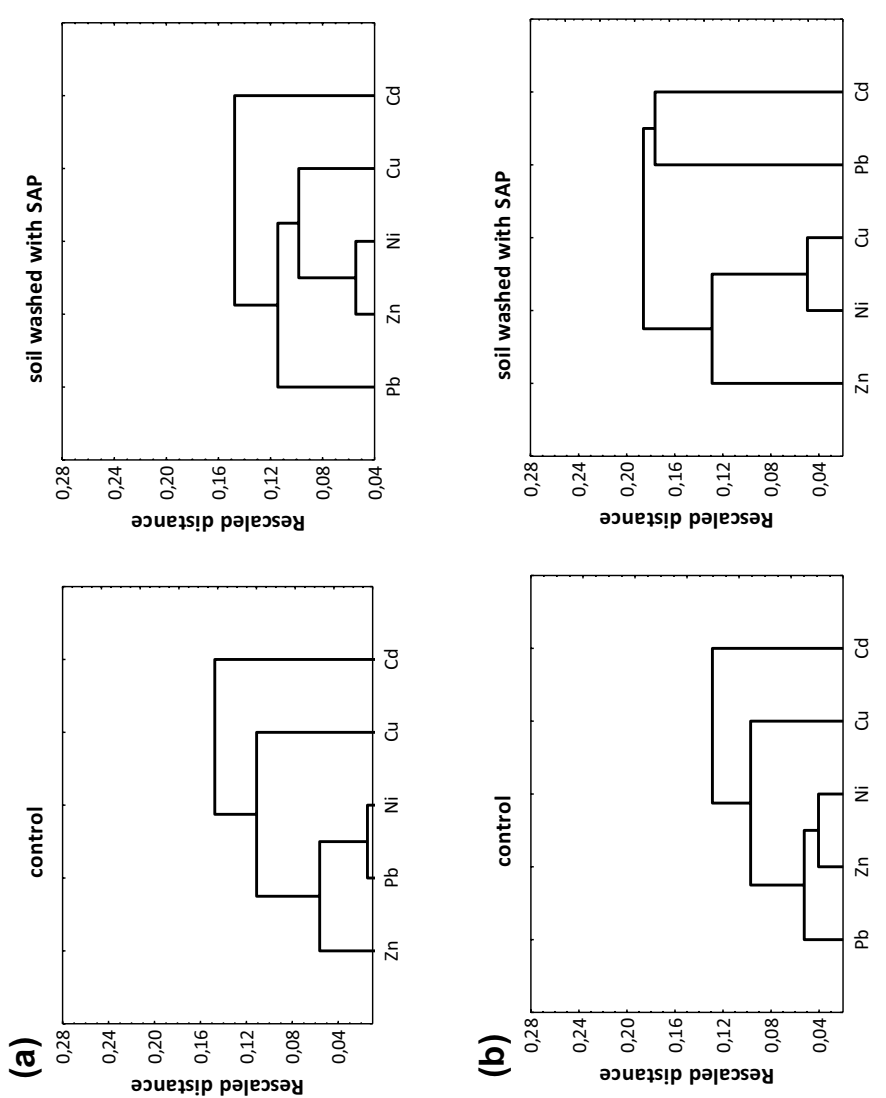
$\mathrm{Cu}$ were grouped into a cluster, and after washing this soil with RAM, $\mathrm{Zn}$ and $\mathrm{Pb}$ were in a cluster (Fig. 5b).

\section{The effect of sequential soil washing with biosurfactants on HM removal}

The results of HM removal from soils by sequential soil washing with biosurfactants belonging to the same class or different classes are presented in Fig. 6. With all the combinations of biosurfactants used, sequential soil washing was more effective for removal of all HMs than single soil washing (Fig. 2). This is in agreement with previous studies (Wei et al. 2016; Kulikowska et al. 2015; Gusiatin and Radziemska 2018).

With regard to most $\mathrm{HMs}$ (i.e., $\mathrm{Zn}, \mathrm{Ni}, \mathrm{Cu}$ ), sequential soil washing with plant biosurfactants (SAP-SAP or TAN-TAN) removed more HMs than sequential soil washing with microbial biosurfactants (RAM-RAM). In contrast, $\mathrm{Pb}$ removal with RAM-RAM washing was much more effective than with SAP-SAP or TAN-TAN washing. RAM-RAM washing was also more effective than TAN-TAN washing for removing Cd from soil 1 and soil 2 .

In the present study, sequential soil washing with different classes of biosurfactants was beneficial for simultaneous removal of multi-HMs. With the TAN-RAM sequence, the efficiency of $\mathrm{Ni}, \mathrm{Cd}, \mathrm{Pb}$ and $\mathrm{Zn}$ removal from both soils was higher than the efficiency of their removal with TAN-TAN. For removal of $\mathrm{Cu}, \mathrm{Zn}$ and $\mathrm{Ni}, \mathrm{SAP}-\mathrm{RAM}$ washing had slightly lower or similar efficiency to washing with SAP only. However, for removal of $\mathrm{Pb}$ from both soils and $\mathrm{Cd}$ from soil 1, SAP-RAM was more efficient than SAP-SAP. Sequential soil washing with SAP-RAM and TAN-RAM removed more $\mathrm{Zn}$ and $\mathrm{Ni}$ than sequential washing with RAM-RAM.

Sequential soil washing can first remove the more easily extracted HM fractions (e.g., exchangeable) and then remove the more difficult-to-extract fractions (e.g., carbonate and reducible) (Gusiatin and Klimiuk 2012). In the case of soil contaminated with multi-HMs, the HMs are not always completely removed from the exchangeable fraction after the first washing because the HMs compete for the active sites on the biosurfactant. This competition limits the number of active sites on the surface of the biosurfactant that are available for simultaneous removal of HMs. Moreover, after each washing cycle, a new equilibrium distribution of contaminants is established (Ye et al. 2014). Therefore, adding fresh biosurfactant solution in successive washings provides new active sites for HM complexation and partially can enable removal of HMs that are in the more difficult-to-remove fractions.

Kulikowska et al. (2015) noticed that, even with threestep soil washing with humic substances, one class of extractant may not be sufficient for removing HMs from soils heavily contaminated with multi-HMs. Thus, as with other washing agents, sequential extraction using extractants other than humic substances may be needed to remove multi-HMs from soil. Sequential soil washing with the use of different biosurfactants in each washing step can increase the efficiency of removal of different HMs due to complementary HM complexation caused by differences in the affinity of HMs for a given biosurfactant. For example, Beiyuan et al.
Fig. 6 HM removal efficiencies after sequential soil washing with different combinations of biosurfactants: a soil 1 , b soil 2. For a given HM, efficiency values followed by the same letters do not differ significantly at $p<0.05$
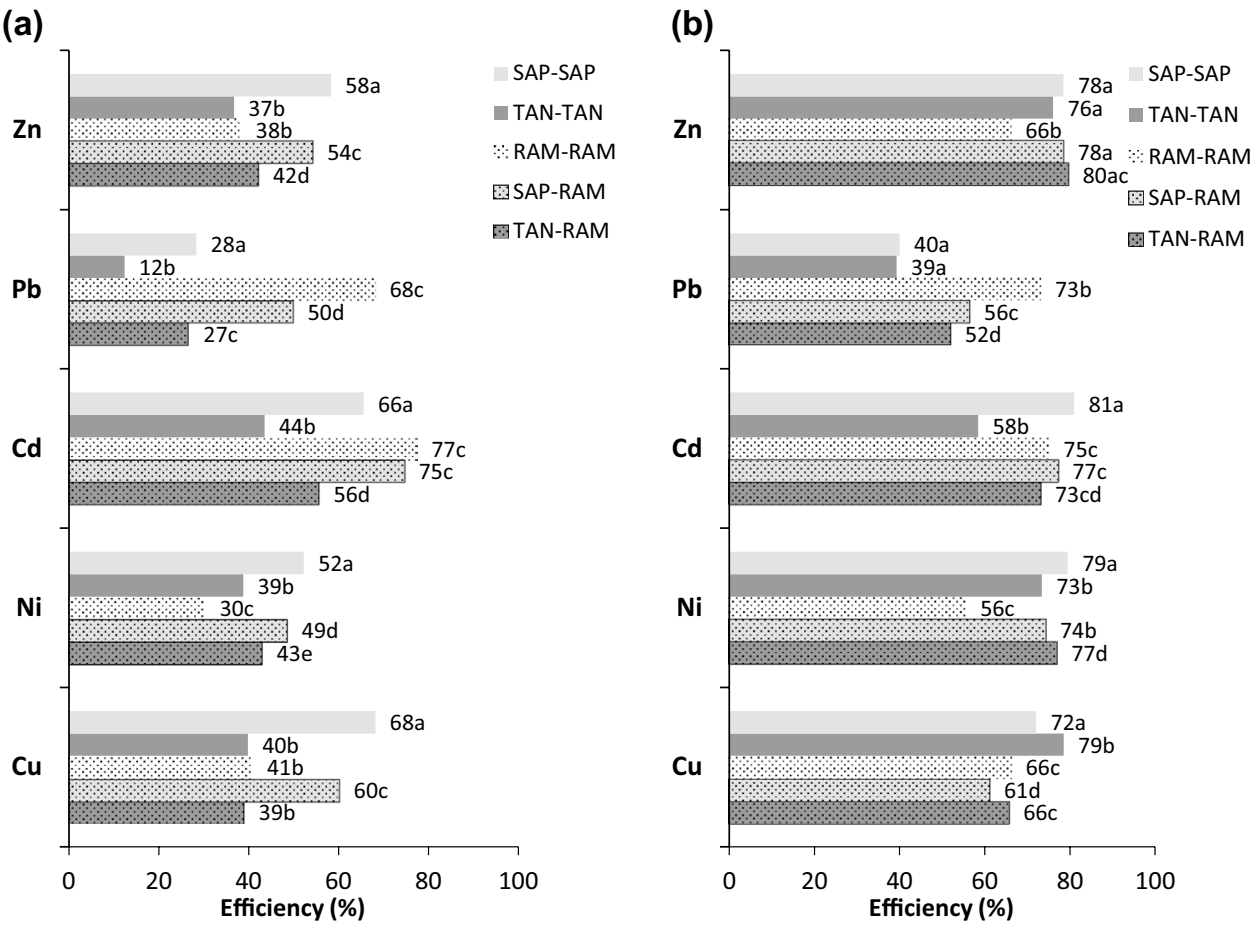
(2018) observed that, under various soil washing schemes, the complementary action of EDTA and EDDS led to better $\mathrm{Cu}$ and $\mathrm{Pb}$ removal with a mixture of these washing agents than with EDDS alone.

\section{Conclusions}

Application of SAP, TAN or RAM gave better results for treatment of soil that was less contaminated with HMs and aged for a shorter period of time than for treatment of soil that was more contaminated with these metals and aged for a longer time. When an individual HM had a lower stability (as $I_{R}$ ) in one soil than in the other, more of that HM was removed from the soil in which the $I_{\mathrm{R}}$ was lower. However, when comparing different HMs in the same soil, this association between $I_{\mathrm{R}}$ and HM removal was not always observed. This suggests that the affinity of a given biosurfactant for a particular HM was more important than the stability of that HM. Regardless of the soil properties, soil age and level of soil contamination with HMs, SAP was most effective for $\mathrm{Cu}, \mathrm{Ni}$ and $\mathrm{Zn}$ removal, whereas RAM was most effective for $\mathrm{Cd}$ and $\mathrm{Pb}$ removal. TAN was less effective for $\mathrm{Cu}, \mathrm{Ni}$ and $\mathrm{Zn}$ removal than SAP, but more effective than RAM. All biosurfactants effectively removed the HMs from the ready available fraction and partially removed these metals from the potentially labile fraction (including the mainly reducible fraction). Although SAP, TAN and RAM did not completely remove the HMs, they changed their distribution and substantially increased their stability in soil.

The results of the present study suggest that, for treatment of multi-HM-contaminated soils, and especially those co-contaminated with $\mathrm{Pb}$, sequential soil washing with plant biosurfactants and then with microbial rhamnolipids could remove metals more efficiently than a single washing or sequential washing employing the same class of biosurfactant in each step.

Acknowledgements The study was supported by the Ministry of Science and Higher Education in Poland (Statutory Research, 18.610.006-300).

Open Access This article is distributed under the terms of the Creative Commons Attribution 4.0 International License (http://creativeco mmons.org/licenses/by/4.0/), which permits unrestricted use, distribution, and reproduction in any medium, provided you give appropriate credit to the original author(s) and the source, provide a link to the Creative Commons license, and indicate if changes were made.

\section{References}

Açıkel YS (2011) Use of biosurfactants in the removal of heavy metal ions from soils. Springer, Dordrecht
Akintunde TA, Abioye OP, Oyeleke SB et al (2015) Remediation of iron using rhamnolipid-surfactant produced by Pseudomonas aeruginosa. Res J Environ Sci 9:169-177. https://doi.org/10.3923/ rjes.2015.169.177

Alloway BJ (1995) Heavy metals in soils. Blackie Academic and Professional, Chapman and Hall, London, p 368. https://doi. org/10.1007/978-94-011-1344-1

Beiyuan J, Tsang DC, Valix M et al (2018) Combined application of EDDS and EDTA for removal of potentially toxic elements under multiple soil washing schemes. Chemosphere 205:178187. https://doi.org/10.1016/j.chemosphere.2018.04.081

Bilgin M, Tulun S (2016) Removal of heavy metals ( $\mathrm{Cu}, \mathrm{Cd}$ and $\mathrm{Zn}$ ) from contaminated soils using EDTA and $\mathrm{FeCl}_{3}$. Glob NEST J 18(1):98-107. https://doi.org/10.30955/gnj.001732

Cao C, Zhang Q, Ma Z-B et al (2018) Fractionation and mobility risks of heavy metals and metalloids in wastewater-irrigated agricultural soils from greenhouses and fields in Gansu, China. Geoderma 328:1-9. https://doi.org/10.1016/j.geode rma.2018.05.001

Chen WJ, Hsiao LC, Chen KKY (2008) Metal desorption from copper(II)/nickel(II)-spiked kaolin as a soil component using plant-derived saponin biosurfactant. Process Biochem 43(5):488-498. https://doi.org/10.1016/j.procbio.2007.11.017

Deng H, Yang Y, Li Z et al (2015) Leaching remediation of copper and lead contaminated Lou soil by saponin under different conditions. Huan jing ke xue 36:1445-1452

Evans LJ (1989) Chemistry of metal retention by soils. Environ Sci Technol 23:1046-1056. https://doi.org/10.1021/es00067a001

Friman L, Höglund H, Högberg H-E (2004) Tannin-iron impregnated thermomechanical pulp. Part I: effects of extractions and heat on brightness. Nord Pulp Pap Res J 19:229-236. https://doi. org/10.3183/NPPRJ-2004-19-02-p229-236

Ghayoraneh M, Qishlaqi A (2017) Concentration, distribution and speciation of toxic metals in soils along a transect around a $\mathrm{Zn} /$ $\mathrm{Pb}$ smelter in the northwest of Iran. J Geochem Explor 180:114. https://doi.org/10.1016/j.gexplo.2017.05.007

Gusiatin ZM (2014) Tannic acid and saponin for removing arsenic from brownfield soils: mobilization, distribution and speciation. J Environ Sci 26(4):855-864. https://doi.org/10.1016/S1001 -0742(13)60534-3

Gusiatin ZM, Klimiuk E (2012) Metal (Cu, Cd and Zn) removal and stabilization during multiple soil washing by saponin. Chemosphere 86:383-391. https://doi.org/10.1016/j.chemospher e.2011.10.027

Gusiatin ZM, Radziemska M (2018) Saponin versus rhamnolipids for remediation of $\mathrm{Cd}$ contaminated soils. Clean Soil Air Water 46(3):1700071-1700080. https://doi.org/10.1002/clen.20170 0071

Gusiatin ZM, Bułkowska K, Pokój T (2014) Tannic acid as a cost-effective substitute for saponin in soil remediation. Environ Biotechnol 10:66-72. https://doi.org/10.14799/ebms240

Han FX, Banin A, Kingery WL et al (2003) New approach to studies of heavy metal redistribution in soil. Adv Environ Res 8:113-120. https://doi.org/10.1016/S1093-0191(02)00142-9

Hong K-J, Tokunaga S, Kajiuchi T (2002) Evaluation of remediation process with plant-derived biosurfactant for recovery of heavy metals from contaminated soils. Chemosphere 49:379-387. https ://doi.org/10.1016/S0045-6535(02)00321-1

Juwarkar AA, Nair A, Dubey KV et al (2007) Biosurfactant technology for remediation of cadmium and lead contaminated soils. Chemosphere 68:1996-2002. https://doi.org/10.1016/j.chemospher e. 2007.02 .027

Juwarkar AA, Dubey KV, Nair A, Singh SK (2008) Bioremediation of multi-metal contaminated soil using biosurfactant-a novel approach. Indian J Microbiol 48:142-146. https://doi.org/10.1007/ s12088-008-0014-5 
Kabala C, Singh BR (2001) Fractionation and mobility of copper, lead, and zinc in soil profiles in the vicinity of a copper smelter. J Environ Qual 30(2):485-492. https://doi.org/10.2134/jeq2001.30248 $5 \mathrm{x}$

Karamać M, Karamać M (2009) Chelation of Cu(II), Zn(II), and $\mathrm{Fe}(\mathrm{II})$ by tannin constituents of selected edible nuts. Int J Mol Sci 10:5485-5497. https://doi.org/10.3390/ijms10125485

Khalid S, Shahid M, Niazi NK et al (2017) A comparison of technologies for remediation of heavy metal contaminated soils. J Geochem Explor 182:247-268. https://doi.org/10.1016/j.gexpl o.2016.11.021

Kulikowska D, Gusiatin ZM, Bułkowska K, Klik B (2015) Feasibility of using humic substances from compost to remove heavy metals $(\mathrm{Cd}, \mathrm{Cu}, \mathrm{Ni}, \mathrm{Pb}, \mathrm{Zn})$ from contaminated soil aged for different periods of time. J Hazard Mater 300:882-891. https://doi. org/10.1016/j.jhazmat.2015.08.022

Kuziemska B, Kalembasa S, Wieremiej W (2014) Distribution of nickel in fractions extracted with the BCR procedure from nickelcontaminated soil. J Elem 19(3):697-708. https://doi.org/10.5601/ jelem.2014.19.3.702

Liu Z, Li Z, Zhong H et al (2017) Recent advances in the environmental applications of biosurfactant saponins: a review. J Environ Chem Eng 5:6030-6038. https://doi.org/10.1016/j.jece.2017.11.021

Liu G, Zhong H, Yang X et al (2018) Advances in applications of rhamnolipids biosurfactant in environmental remediation: a review. Biotechnol Bioeng 115:796-814. https://doi.org/10.1002/ bit. 26517

Mulligan CN, Wang S (2006) Remediation of a heavy metal-contaminated soil by a rhamnolipid foam. Eng Geol 85:75-81. https://doi. org/10.1016/j.enggeo.2005.09.029

Naghipour D, Jaafari J, Ashrafi SD, Mahvi AH (2017) Remediation of heavy metals contaminated silty clay loam soil by column extraction with ethylenediaminetetraacetic acid and nitrilo triacetic acid. J Environ Eng 143(8):04017026. https://doi.org/10.1061/(asce) ee.1943-7870.0001219

Neilson JW, Artiola JF, Maier RM (2003) Characterization of lead removal from contaminated soils by nontoxic soil-washing agents. J Environ Qual 32:899-908. https://doi.org/10.2134/jeq2003.0899

Ochoa-Loza FJ, Artiola JF, Maier RM (2001) Stability constants for the complexation of various metals with a rhamnolipid biosurfactant. J Environ Qual 30:479-485

Ostrowska A, Gawliński S, Szczubiałka Z (1991) Methods of analysis and assessment of soil properties and plants. Institute of Environmental Protection, Warsaw (in Polish)

Pueyo M, Mateu J, Rigol A et al (2008) Use of the modified BCR threestep sequential extraction procedure for the study of trace element dynamics in contaminated soils. Environ Pollut 152:330-341. https://doi.org/10.1016/j.envpol.2007.06.020

Slizovskiy IB, Kelsey JW, Hatzinger PB (2011) Surfactant-facilitated remediation of metal-contaminated soils: efficacy and toxicological consequences to earthworms. Environ Toxicol Chem 30:112123. https://doi.org/10.1002/etc.357

Tang J, He J, Liu T, Xin X (2017) Removal of heavy metals with sequential sludge washing techniques using saponin: optimization conditions, kinetics, removal effectiveness, binding intensity, mobility and mechanism. RSC Adv 7(53):33385-33401. https:// doi.org/10.1039/C7RA04284A

Tang W, Xia Q, Shan B, Ng JC (2018) Relationship of bioaccessibility and fractionation of cadmium in long-term spiked soils for health risk assessment based on four in vitro gastrointestinal simulation models. Sci Total Environ 631-632:1582-1589. https://doi. org/10.1016/j.scitotenv.2018.03.154

Tewari G, Tewari L, Srivastava PC, Ram B (2010) Nickel chemical transformation in polluted soils as affected by metal source and moisture regime. Chem Speciat Bioavailab 22:141-155. https:// doi.org/10.3184/095422910X12826770835261

Urum K, Pekdemir T (2004) Evaluation of biosurfactants for crude oil contaminated soil washing. Chemosphere 57(9):1139-1150. https ://doi.org/10.1016/j.chemosphere.2004.07.048

Venkatesh NM, Vedaraman N (2012) Remediation of soil contaminated with copper using Rhamnolipids produced from Pseudomonas aeruginosa MTCC 2297 using waste frying rice bran oil. Ann Microbiol 62:85-91. https://doi.org/10.1007/s13213-011-0230-9

Wan J, Meng D, Long T et al (2015) Simultaneous removal of lindane, lead and cadmium from soils by rhamnolipids combined with citric acid. PLoS One 10:e0129978. https://doi.org/10.1371/journ al.pone. 0129978

Wei M, Chen J, Wang X (2016) Removal of arsenic and cadmium with sequential soil washing techniques using Na2EDTA, oxalic and phosphoric acid: optimization conditions, removal effectiveness and ecological risks. Chemosphere 156:252-261. https://doi. org/10.1016/j.chemosphere.2016.04.106

Scheinost AC, Abend S, Pandya KI, Sparks DL (2001) Kinetic controls on $\mathrm{Cu}$ and $\mathrm{Pb}$ sorption by ferrihydrite. Environ Sci Tchnol 35:1090-1096

Yang Z, Zhang S, Liao Y et al (2012) Remediation of heavy metal contamination in calcareous soil by washing with reagents: a column washing. Procedia Environ Sci 16:778-785. https://doi. org/10.1016/j.proenv.2012.10.106

Ye M, Sun M, Kengara FO et al (2014) Evaluation of soil washing process with carboxymethyl- $\beta$-cyclodextrin and carboxymethyl chitosan for recovery of PAHs/heavy metals/fluorine from metallurgic plant site. J Environ Sci 26(8):1661-1672. https://doi. org/10.1016/j.jes.2014.06.006

Zhan H, Jiang Y, Wang B et al (2012) Study on removal efficiencies and mechanism of heavy metal from sewage-irrigated soils by saponin compared with commonly used washing agents. Int J Sci Eng Res 3(11):461-469

Zhang H, Wang Z, Gao Y (2018) Compound washing remediation and response surface analysis of lead-contaminated soil in mining area by fermentation broth and saponin. Environ Sci Pollut Res Int 25:6899-6908. https://doi.org/10.1007/s11356-017-0971-5

Publisher's Note Springer Nature remains neutral with regard to jurisdictional claims in published maps and institutional affiliations. 